University of Tennessee Health Science Center UTHSC Digital Commons

$12-2013$

\title{
Developmental Characterization of the Choroid Plexus in Sialidosis (Neu1 Deficient) Mice
}

Danielle Lee Helton

University of Tennessee Health Science Center

Follow this and additional works at: https://dc.uthsc.edu/dissertations

Part of the Neurosciences Commons

\section{Recommended Citation}

Helton, Danielle Lee , "Developmental Characterization of the Choroid Plexus in Sialidosis (Neu1 Deficient) Mice" (2013). Theses and Dissertations (ETD). Paper 342. http://dx.doi.org/10.21007/ etd.cghs.2013.0132.

This Dissertation is brought to you for free and open access by the College of Graduate Health Sciences at UTHSC Digital Commons. It has been accepted for inclusion in Theses and Dissertations (ETD) by an authorized administrator of UTHSC Digital Commons. For more information, please contact jwelch30@uthsc.edu. 


\title{
Developmental Characterization of the Choroid Plexus in Sialidosis (Neu1 Deficient) Mice
}

\begin{abstract}
The lysosomal sialidase Neuraminidase-1 (Neu1) initiates the hydrolysis of sialoglycoconjugates by cleaving their terminal sialic acid residues. Neu1 creates a complex with the carboxypeptidase protective protein/cathepsin A (PPCA), which is necessary for its catalytic activation and its transport to the lysosomal compartment. In humans, a primary deficiency of this enzyme leads to a pediatric, catastrophic, neurodegenerative lysosomal storage disorder called sialidosis. Mice deficient in Neu1 exemplify the early-onset severe form of sialidosis. Our laboratory has recently discovered that loss of Neu1 exacerbates the process of lysosomal exocytosis (LyEXO) in various cell types by influencing the sialic acid content of lysosomal associated membrane protein-1 (LAMP-1). LyEXO is a calcium-regulated physiological process which results in the fusion of lysosomes with the plasma membrane and consequent remodeling of the PM and release of lysosomal luminal content into the extracellular space. Defective processing of the sialic acid residues of LAMP-1 in absence of Neu1, prolongs its half-life and leaves lysosomes disposed to dock at the PM and take part in LyEXO. So far, Neu1 deficient mice are the only disease model currently available that shows excessive LyEXO.

This dissertation focused on a brain structure, which has an intrinsic exocytic/endocytic capacity: the choroid plexus (CP). The CP is responsible for producing and secreting the cerebrospinal fluid (CSF) and functions as the barrier interface between the blood and the CSF. The specific aim of this research was to investigate the consequences of Neu1 deficiency on the structural and functional characteristics of the $\mathrm{CP}$ as assessed by a comprehensive analysis of several CP markers during development and adulthood.
\end{abstract}

\section{Document Type}

Dissertation

Degree Name

Doctor of Philosophy (PhD)

Program

Biomedical Sciences

Research Advisor

Alessandra d'Azzo, Ph.D.

\section{Keywords}

choroid plexus, lysosomal storage disorders, lysosomes, sialidosis, tight junctions

\section{Subject Categories}

Medical Sciences | Medicine and Health Sciences | Neurosciences

\section{Comments}

One year embargo expired December 2014 


\title{
Danielle Lee Helton
}

Document Type:

Name:

Email Address:

Title:

Degree:

Major:

Program:

Track:

Research Advisor:

Advisor's Email:

Committee Members:

Keywords:

Availability:

Graduation Date:
Doctoral Dissertation

Danielle Lee Helton

dee.helton5@gmail.com

Developmental Characterization of the Choroid Plexus in Sialidosis (Neul Deficient) Mice

Doctor of Philosophy

NA

Integrated Program in Biomedical Sciences

Neuroscience

Alessandra d'Azzo, Ph.D.

sandra.dazzo@stjude.org

Matthew Ennis, Ph.D.

Gerard Grosveld, Ph.D.

Karen A. Hasty, Ph.D.

Michael R. Taylor, Ph.D.

choroid plexus, lysosomal storage disorders, lysosomes, sialidosis, tight junctions

One year embargo

December 2013

\begin{abstract}
The lysosomal sialidase Neuraminidase-1 (Neu1) initiates the hydrolysis of sialoglycoconjugates by cleaving their terminal sialic acid residues. Neul creates a complex with the carboxypeptidase protective protein/cathepsin A (PPCA), which is necessary for its catalytic activation and its transport to the lysosomal compartment. In humans, a primary deficiency of this enzyme leads to a pediatric, catastrophic, neurodegenerative lysosomal storage disorder called sialidosis. Mice deficient in Neu1 exemplify the early-onset severe form of sialidosis. Our laboratory has recently discovered that loss of Neul exacerbates the process of lysosomal exocytosis (LyEXO) in various cell types by influencing the sialic acid content of lysosomal associated membrane protein-1 (LAMP-1). LyEXO is a calcium-regulated physiological process which results in the fusion of lysosomes with the plasma membrane and consequent remodeling
\end{abstract}


of the PM and release of lysosomal luminal content into the extracellular space. Defective processing of the sialic acid residues of LAMP-1 in absence of Neu1, prolongs its half-life and leaves lysosomes disposed to dock at the PM and take part in LyEXO. So far, Neul deficient mice are the only disease model currently available that shows excessive LyEXO.

This dissertation focused on a brain structure, which has an intrinsic exocytic/endocytic capacity: the choroid plexus $(\mathrm{CP})$. The $\mathrm{CP}$ is responsible for producing and secreting the cerebrospinal fluid (CSF) and functions as the barrier interface between the blood and the CSF. The specific aim of this research was to investigate the consequences of Neul deficiency on the structural and functional characteristics of the $\mathrm{CP}$ as assessed by a comprehensive analysis of several CP markers during development and adulthood.

\section{Attached File(s)}

pdf (7.7 Mbytes). This pdf best viewed using the latest version of Acrobat Reader. .

| Back to ETD Index Page $\mid$ Back to CGHS Home Page $\mid$ 